\title{
A Review of Surface Analysis Techniques for the Investigation of the Phenomenon of Electrochemical Promotion of Catalysis with Alkaline Ionic Conductors
}

\author{
Jesús González-Cobos and Antonio de Lucas-Consuegra * \\ Received: 30 November 2015; Accepted: 6 January 2016; Published: 18 January 2016 \\ Academic Editor: Michalis Konsolakis \\ Department of Chemical Engineering, School of Chemical Sciences and Technologies, \\ University of Castilla-La Mancha, Ave. Camilo José Cela 12, 13005 Ciudad Real, Spain; \\ jesus.gonzalez.cobos@gmail.com \\ * Correspondence: Antonio.lconsuegra@uclm.es; Tel.: +34-926-295-300; Fax: +34-926-295-437
}

\begin{abstract}
Electrochemical Promotion of Catalysis (EPOC) with alkali ionic conductors has been widely studied in literature due to its operational advantages $v s$. alkali classical promotion. This phenomenon allows to electrochemically control the alkali promoter coverage on a catalyst surface in the course of the catalytic reaction. Along the study of this phenomenon, a large variety of in situ and ex situ surface analysis techniques have been used to investigate the origin and mechanism of this kind of promotion. In this review, we analyze the most important contributions made on this field which have clearly evidenced the presence of adsorbed alkali surface species on the catalyst films deposited on alkaline solid electrolyte materials during EPOC experiments. Hence, the use of different surface analysis techniques such as scanning electron microscopy (SEM), energy-dispersive X-ray spectroscopy (EDX), X-ray diffraction (XRD), X-ray photoelectron spectroscopy (XPS), scanning photoelectron microscopy (SPEM), or scanning tunneling microscopy (STM), led to a better understanding of the alkali promoting effect, and served to confirm the theory of electrochemical promotion on this kind of catalytic systems. Given the functional similarities between alkali electrochemical and chemical promotion, this review aims to bring closer this phenomenon to the catalysis scientific community.
\end{abstract}

Keywords: electrochemical activation; EPOC; alkali promotion; surface analysis; ionic conductors; active catalyst supports; sodium; potassium

\section{General Features of Alkaline Electrochemical Promotion}

Promoters are widely used in the heterogeneous catalysis field [1,2]. Structural promoters improve the dispersion and stability of the active phase on the catalyst support, while electronic ones enhance the catalytic properties of the active phase itself. This latter kind of promoters can be added to the catalyst ex situ, i.e., during the catalyst preparation step, or in situ, i.e., in the course of the catalytic reaction, through the phenomenon of Electrochemical Promotion Of Catalysis (EPOC). This phenomenon, also known in literature as "Non-faradaic Electrochemical Modification of Catalytic Activity" (NEMCA effect) [3], is based on the modification of the performance of a catalyst by the electrochemical pumping of promoter ions from an electro-active catalyst support, which is a solid electrolyte material, e.g., $\mathrm{H}^{+}$, $\mathrm{Na}^{+}, \mathrm{K}^{+}, \mathrm{O}^{2-}$, or $\mathrm{F}^{-}$ionic conductors [4]. Although the first works on electrochemical promotion were carried out by using yttria-stabilized zirconia (YSZ), i.e., an $\mathrm{O}^{2-}$ ionic conductor material, as solid electrolyte [5], alkaline conductors such as the $\beta$-alumina family or NASICON-like compounds (e.g., $\mathrm{Na}_{3} \mathrm{Zr}_{2} \mathrm{Si}_{2} \mathrm{PO}_{12}, \mathrm{~K}_{2} \mathrm{YZr}\left(\mathrm{PO}_{4}\right)_{3}$, or $\left.\mathrm{Li}_{14} \mathrm{ZnGe}_{4} \mathrm{O}_{16}\right)$, among others, have also been widely studied on the electrochemical promotion field $[6,7]$. 
In the case of electrochemical catalysts based on alkali $\left(\mathrm{M}^{+}\right)$-conductors, the application of a cathodic polarization (i.e., negative current or overpotential) between the catalyst film-working electrode, which is deposited on one side of the electrolyte, and an inert counter electrode (typically gold) located at the opposite side (see Figure 1) leads to the migration of promoter $\left(\mathrm{M}^{+}\right)$ions to the catalyst film, which is also called as back-spillover phenomenon. Once located over the catalyst surface, as in chemical (classical) promotion, these ionic species modify its chemisorption properties and hence its catalytic performance [3]. Thus, some of the main advantages of electrochemical promotion vs. classical promotion in heterogeneous catalysis are the capability of optimizing the amount of promoter coverage under changing reaction conditions and the possibility of in situ tuning the catalyst performance to maximize its activity and selectivity toward the desired product, even preventing catalyst deactivation or allowing its regeneration. These operational advantages $v$ s. classical promotion, among others, have recently been revised by A. de Lucas-Consuegra [6]. It should also be noted that there are important differences in operating EPOC systems depending on the nature of the employed electro-active catalyst support. When using ionic conductor materials where the supplied ions can also participate in the catalytic reaction under study (e.g., $\mathrm{O}^{2-}$ ions in the case of catalytic oxidations or $\mathrm{H}^{+}$ions in catalytic hydrogenations) then these ions act as "sacrificial promoters" and present a finite mean residence time on the catalyst surface. In these cases, both galvanostatic and potentiostatic operations allow to obtain a steady-state catalytic reaction rate at each applied current or potential, respectively. However, when using solid electrolytes where the ionic conducting species are not involved in the catalytic reaction (e.g., $\mathrm{Na}^{+}$or $\mathrm{K}^{+}$ions) then only potentiostatic operation leads to steady-state reaction rates and, under galvanostatic operation, the coverage of the $M^{+}$promoter, $\theta_{M^{+}}$, increases with time as long as a constant electric current is maintained [3]. However, in these cases, as will be shown later, these alkali ions typically react with co-adsorbed reactant molecules on the gas-exposed catalyst surface leading to the formation of a large variety of promotional species.

\section{ELECTROCHEMICAL PROMOTION (EPOC)}

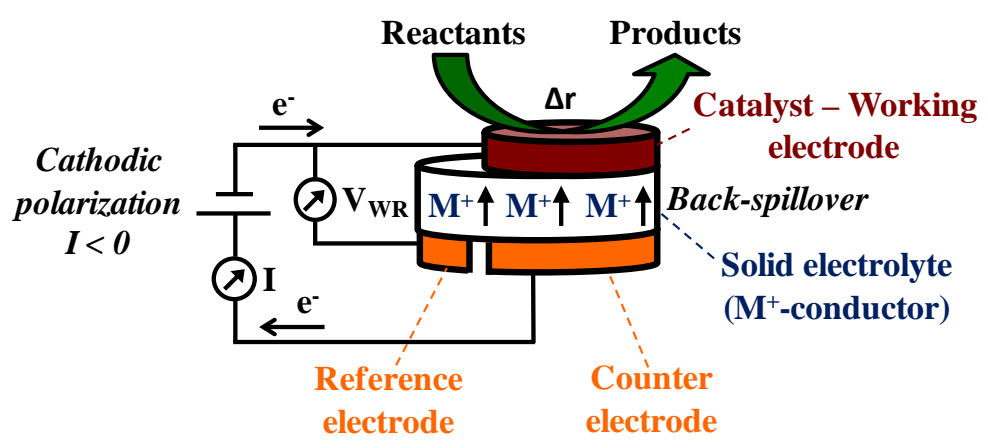

Figure 1. Scheme of the electrochemical cell used in electrochemical promotion studies with an alkaline ionic conductor (generally indicated as $\mathrm{M}^{+}$-conductor) solid electrolytes.

Vayenas et al. performed the first electrochemical promotion study with alkaline solid electrolyte $\left(\mathrm{Na}-\mathrm{\beta Al}_{2} \mathrm{O}_{3}\right)$ in 1991 [8]. From this pioneer work, $\mathrm{Na}^{+}$-conductors have been widely employed in many catalytic systems such as ethylene [9,10], CO [11], propane [12] and propylene oxidation [13], NO reduction [14-16], Fischer Tropsch synthesis [17], or hydrogenation of benzene [18] and $\mathrm{CO}_{2}$ [19]. On the other hand, the first EPOC study using a $\mathrm{K}^{+}$-conductor electrolyte $\left(\mathrm{K}_{2} \mathrm{YZr}\left(\mathrm{PO}_{4}\right)_{3}\right)$ dates from 1997 and addressed the Fe-catalyzed ammonia decomposition [20]. Urquhart et al. used other $\mathrm{K}^{+}$-conductor solid electrolyte $\left(\mathrm{K}-\mathrm{\beta Al}_{2} \mathrm{O}_{3}\right)$ in Fischer-Tropsch reaction studies under both atmospheric [21] and high pressure [22], and de Lucas-Consuegra et al. introduced the use of this kind of ion-conducting catalyst support for the electrochemical promotion of $\mathrm{Pt}$ in $\mathrm{CO}$ [23] and propylene [24] oxidation, as well as in $\mathrm{NO}_{x}$ reduction reactions $[25,26]$. More recent alkaline electrochemical promotion studies on $\mathrm{CO}_{2}$ hydrogenation [27-30] and methanol conversion reactions [31-33] should also be 
highlighted. Additionally, in order to understand the mechanism of the phenomenon of electrochemical promotion of catalysis with both anionic and cationic conductors, a wide variety of characterization techniques have been used in the fields of catalysis (e.g., TPD, TPO, or work function measurement), electrochemistry (e.g., cyclic/linear sweep voltammetry or impedance spectroscopy), and surface science (e.g., XPS, UPS, SPEM, or STM) [3]. This paper aims to summarize the most relevant contributions relative to the latter techniques carried out in literature on electrochemical promotion with alkaline conductors. For this purpose, the surface characterization studies summarized in the next two sections have been divided into two categories, depending on whether they were performed under potentiostatic/galvanostatic control (in situ analysis) or not (ex situ analysis), as schematically shown in Figure 2. All these techniques have contributed to the further understanding of the alkali electro-promotional effect in good agreement with the general rules of chemical and electrochemical promotion, valid for the different kinds of electronic promoters (both anionic and cationic ones) [3].

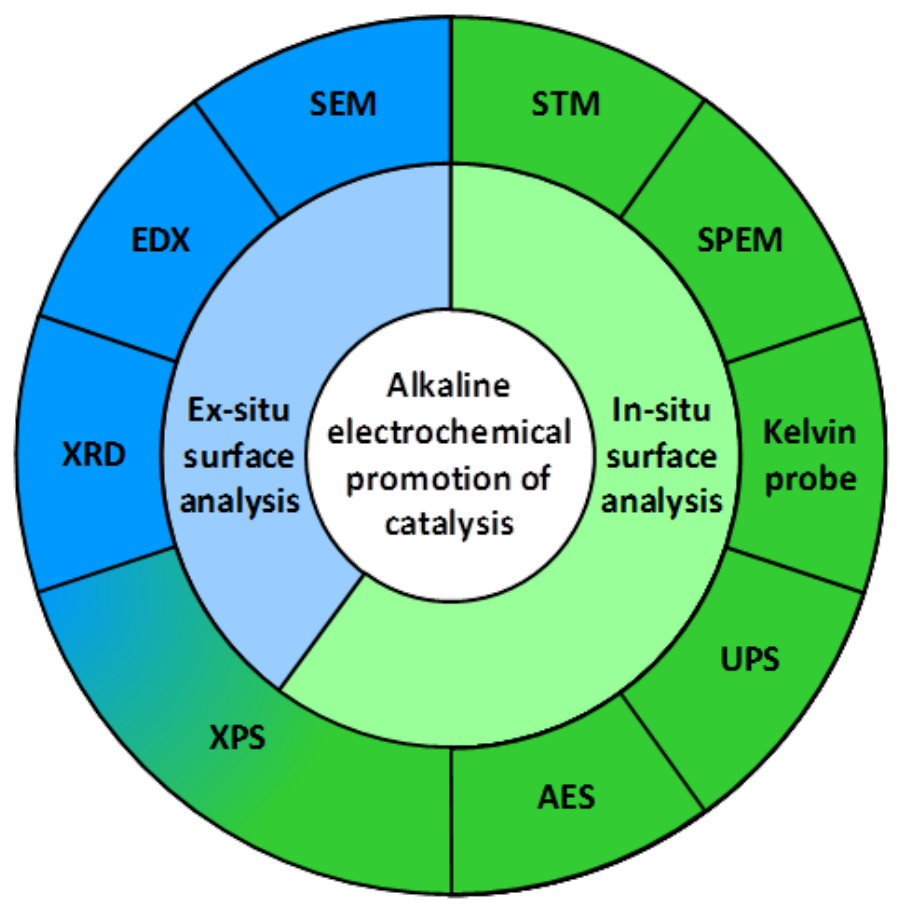

Figure 2. Scheme of the different surface analysis techniques used for investigating alkaline Electrochemical Promotion effect.

\section{Ex Situ Characterization of Alkali-Promoted Catalyst Surfaces}

The post-reaction characterization and analysis of the surface state of a catalyst film, previously subjected to given electrochemical promotion conditions, can be carried out ex situ by the following generic procedure. In the first place, the catalyst film is exposed to the reaction mixture while applying a certain positive or negative overpotential (for establishing an unpromoted or electropromoted state, respectively). After a given time, the reactor is cooled down to room temperature at the same applied overpotential. Then, the reactor and pipe lines are swept with inert gas and open-circuit conditions are established when the temperature is below $373 \mathrm{~K}$ (approximately), i.e., when alkali ions mobility is too low. Finally, the electrochemical catalyst is transferred, under inert atmosphere, from the reactor to the characterization equipment. The aim of this procedure is to "freeze out" the catalyst surface state pertaining to the desired unpromoted/electropromoted state.

SEM and other microscopy techniques are widely employed in catalysis field to evaluate the structure and morphology of the catalysts. In EPOC studies, this technique, together with Energy-dispersive X-ray (EDX) spectroscopy, has also been employed to identify the arrangement 
and nature of the promoter phases present on the catalyst surface. For instance, Figure 3 shows the SEM micrograph, along with the corresponding elemental mapping and spectra by EDX, of a selected region of a $\mathrm{Cu}$ catalyst film deposited on a $\mathrm{K}-\beta \mathrm{Al}_{2} \mathrm{O}_{3}$ pellet $\left(\mathrm{K}^{+}\right.$-conductor) used for the electrochemical promotion of the methanol partial oxidation reaction [32]. Prior to the surface analysis, the catalyst was subjected to certain reaction conditions and an applied potential, $V_{\mathrm{WR}}=-0.5 \mathrm{~V}$, such that $\mathrm{K}^{+}$promoter ions were electrochemically supplied to the catalyst surface. As a consequence, in these micrographs, a large concentration of potassium (in blue) was found on the Cu catalyst surface (in green). This demonstrated that $\mathrm{K}^{+}$ions were able to migrate through the catalyst film and reached the gas-exposed catalyst surface. As also revealed by the EDX analysis taken from different areas of the micrograph (Figure 3c1,c2), oxygen- and potassium-containing surface compounds seemed to be formed on the metal catalyst film during the EPOC experiments, probably in form of some potassium oxides or carbonate molecules. In fact, an excess of these surface species (supplied under high cathodic polarization) could block the $\mathrm{Cu}$ active sites causing a decrease in the catalytic reaction rate in agreement with conventional chemical promotion [32]. Furthermore, some nitrogen (in red) was also noticed, homogeneously distributed on the catalyst surface, which was attributed to the $\mathrm{K}^{+}$-promotional effect on the ammonia formation via reaction of hydrogen and nitrogen, both of them present in the gas reaction atmosphere.

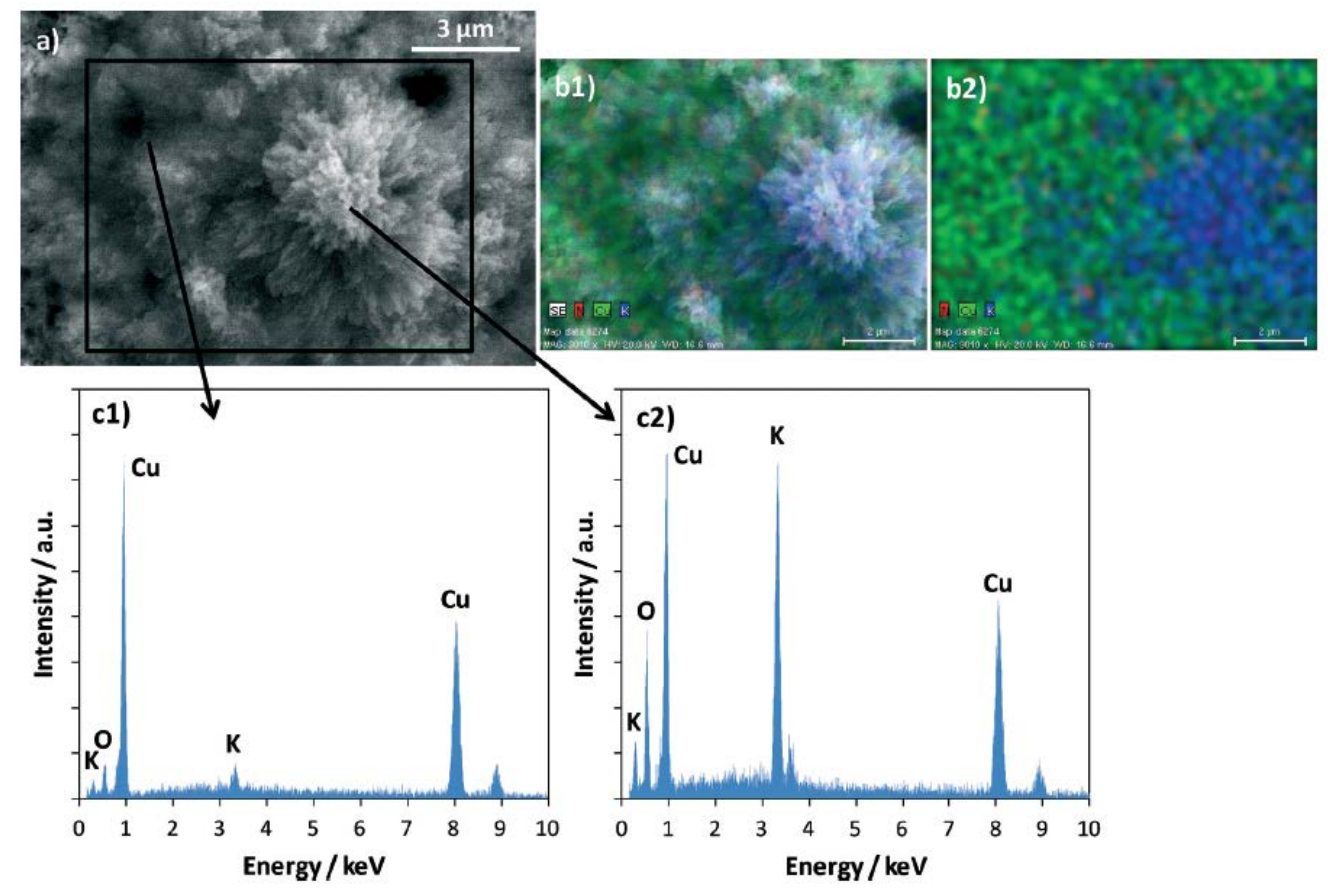

Figure 3. Top view SEM image of a selected area of a $\mathrm{Cu} / \mathrm{K}-\beta \mathrm{Al}_{2} \mathrm{O}_{3}$ electrochemical catalyst (a) after the EPOC experiments $\left(593{ }^{\circ} \mathrm{C}, \mathrm{CH}_{3} \mathrm{OH} / \mathrm{O}_{2}=4.4 \% / 0.3 \%, V_{\mathrm{WR}}=-0.5 \mathrm{~V}\right.$ for $1 \mathrm{~h}$ ), along with the corresponding elemental mapping (b1 and b2) of $\mathrm{Cu}$ (green), $\mathrm{K}$ (blue), and $\mathrm{N}$ (red) and the EDX spectra from different regions (c1 and c2). Reprinted with permission from Ref. [32].

The presence of potassium carbonate/bicarbonate species was also identified on the surface of a promoted $\mathrm{Pt} / \mathrm{K}-\mathrm{\beta Al}_{2} \mathrm{O}_{3}$ electrochemical catalyst employed in a methanol partial oxidation reaction [31]. In this study, these kinds of promoter-derived compounds were also detected ex situ by $X$-ray diffraction analysis after EPOC experiments, as shown in Figure 4. As in the case of the electropromoted $\mathrm{Cu}$ catalyst film, a poisoning effect derived from an excess of $\mathrm{K}^{+}$-derived surface species was found on this Pt film [31]. Furthermore, in both mentioned studies [31,32], the obtained electropromotional effect was completely reversible since all the promoter phases were decomposed and the alkali ions were transferred from the catalyst back to the solid electrolyte after applying a positive enough potential at 
the end of the experiments. In this way, a clean, un-promoted catalyst surface, free of any promoter species, was achieved. These surface species were also observed by SEM-EDX analysis on Pt catalyst films deposited on $\mathrm{K}-\mathrm{\beta Al}_{2} \mathrm{O}_{3}$ solid electrolyte for propene oxidation reaction [24]. In this case, the presence of potassium oxides and superoxides, along with carbon deposited fragments were observed after catalytic experiments. Moreover, these $\mathrm{K}^{+}$-derived species seemed to induce a permanent EPOC effect and showed to be more stable than potassium carbonates or bicarbonates, since the latter needed lower positive potentials to be decomposed. These results demonstrated that the nature of the final form of alkali promoter species and their chemical structure (e.g., oxides, superoxides, carbonates, etc.) strongly influence the final electropromotional behavior.

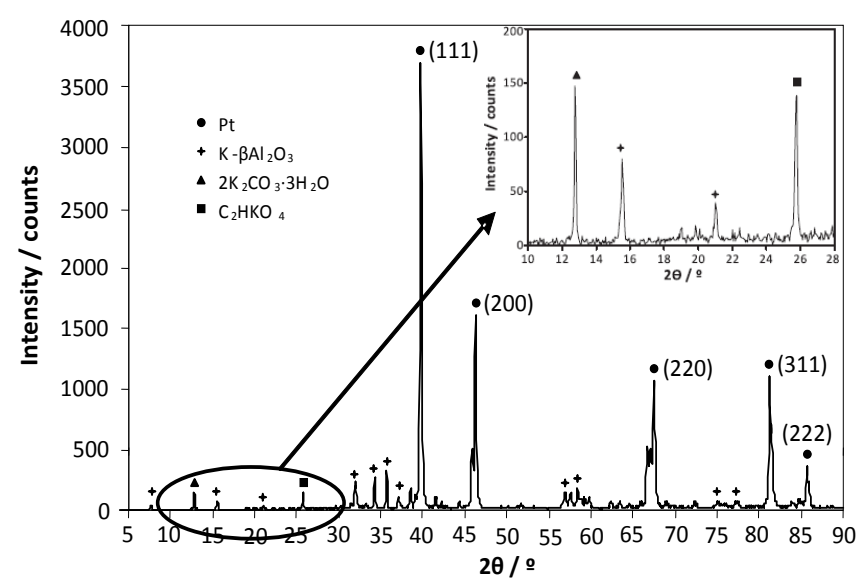

Figure 4. XRD spectra after EPOC experiments $\left(\mathrm{CH}_{3} \mathrm{OH} / \mathrm{O}_{2}=7.2 \% / 4.6 \%\right.$, $593 \mathrm{~K}$, overnight at $\left.-2 \mathrm{~V}\right)$ of a Pt film prepared by impregnation on a $\mathrm{K}-\mathrm{\beta Al}_{2} \mathrm{O}_{3}$ solid electrolyte. Reprinted with permission from Ref. [31].

It should be noted that other characterization techniques such as X-ray photoelectron (XPS) [32] and Fourier transform infrared (FTIR) [24] spectroscopies have also been ex situ employed in the past to study the chemical state of the different alkali promoter species formed on the catalyst surface under EPOC conditions, obtaining similar information about the nature of the different promotional species.

\section{In Situ Characterization of Alkali-Promoted Catalyst Surfaces}

During the alkaline electrochemical promotion of a catalyst film, the influence of the applied potential on the promoter coverage, as well as the nature and stability of the alkali-derived surface species, can be in situ evaluated by different techniques. Indeed, the progress made in the development and understanding of the phenomenon of electrochemical promotion over the years could not be conceived without the in situ spectroscopy studies performed by the group of professor Lambert and co-workers [34-45]. In all cases, the spectra were obtained immediately after exposing the appropriately polarized catalyst film (either unpromoted or electrochemically promoted) to conditions of temperature and reactant partial pressures similar to those encountered in the electrochemical promotion reactor, in order to simulate the different surface conditions of interest. For this purpose, spectrometers equipped with a reaction cell (under galvanostatic/potentiostatic control) and an ultra high vacuum chamber were used, in such a way that the electropromoted sample was mounted on a manipulator that allowed its translation between both chambers.

X-ray photoelectron spectroscopy (XPS) and Auger electron spectroscopy (AES) measurements have been carried out on $\mathrm{Pt}[34-38,40], \mathrm{Rh}[39,41-43]$ and $\mathrm{Cu}[41,44,45]$ catalyst films used in alkaline electrochemical promotion studies for the oxidation of ethylene [34] or propene [37], hydrogenation of acetylene [38], and reduction of NO by $\mathrm{CO}[36,40-45]$ or by propene $[35,39,42,43]$. In first place, all these studies demonstrated that the mode of operation of the electrochemically promoted catalyst films involves reversible pumping (backspillover) of $\mathrm{Na}^{+}$or $\mathrm{K}^{+}$ions from the solid electrolyte in 
agreement with the theory and rules of Electrochemical Promotion of Catalysis. For instance, Figure 5a shows the Na $1 \mathrm{~s}$ XPS spectra obtained on a $\mathrm{Rh}$ catalyst supported on $\mathrm{Na}-\mathrm{\beta Al}_{2} \mathrm{O}_{3}$, at $580 \mathrm{~K}$, as a function of catalyst potential $\left(V_{\mathrm{WR}}\right)$ under ultra-high vacuum conditions [41]. The $+1 \mathrm{~V}$ spectrum corresponds to the clean (unpromoted) sample, while increasingly negative values of $V_{\mathrm{WR}}$ correspond to increasing amounts of electropumped $\mathrm{Na}^{+}$on the catalyst surface. As typically observed in these studies $[35,38,40-42,44,46]$, the $\mathrm{Na}$ 1s emission comprises two components. The first one exhibits invariant binding energy (BE) and its intensity increases with decreasing $V_{\mathrm{WR}}$, i.e., as $\mathrm{Na}^{+}$ions are electropumped to the catalyst. This is ascribed to sodium at the surface of the (grounded) Rh catalyst film. The second (shaded) component exhibits constant intensity and a systematic shift in apparent BE. This shift is numerically equal to the change in catalyst potential, strongly suggesting that this emission arises from the underlying solid electrolyte, whose electrostatic potential differs from that of the Rh film by the change in $V_{\mathrm{WR}}$. This interpretation was confirmed by the experimental results obtained by grazing exit synchrotron photoemission, where the signal from the electrolyte vanished [46]. As also stated in the other referenced studies, the spectral behaviour was reversible and reproducible as a function of $V_{\mathrm{WR}}$, consistent with the reversible and reproducible catalytic response observed during the electrochemical promotion of the Rh catalyst for the $\mathrm{NO}$ reduction reaction with both $\mathrm{CO}$ and $\mathrm{C}_{3} \mathrm{H}_{6}$ [41]. Hence, as it can be drawn from Figure $5 \mathrm{~b}$, the decrease in the catalyst potential to $-1 \mathrm{~V}$ leads to a linear increase in the $\mathrm{Na}^{+}$coverage $\left(\theta_{\mathrm{Na}^{+}}\right)$, up to around 0.025 monolayers, which may be estimated from the integrated $\mathrm{Na}$ 1s intensity of the component associated with the metal surface [47]. Moreover, the catalyst work function ( $\phi)$ also shows to vary linearly with $V_{\mathrm{WR}}$ in such a low $\theta_{\mathrm{Na}^{+}}$ range. In this case, work function changes were determined by ultraviolet photoelectron spectroscopy (UPS), by measuring the change in secondary electron cutoff in the spectrum relative to the Fermi edge [41], although it can also be in situ measured with a Kelvin probe [48]. Very interestingly, XPS data also allowed verifying that electrochemically pumped sodium is identical in behavior and in chemical state with Na supplied by vacuum deposition from a Na evaporation source [35], which is in very good agreement with the close similarities found between electrochemically-promoted catalysts and conventionally-promoted ones $[35,49]$.

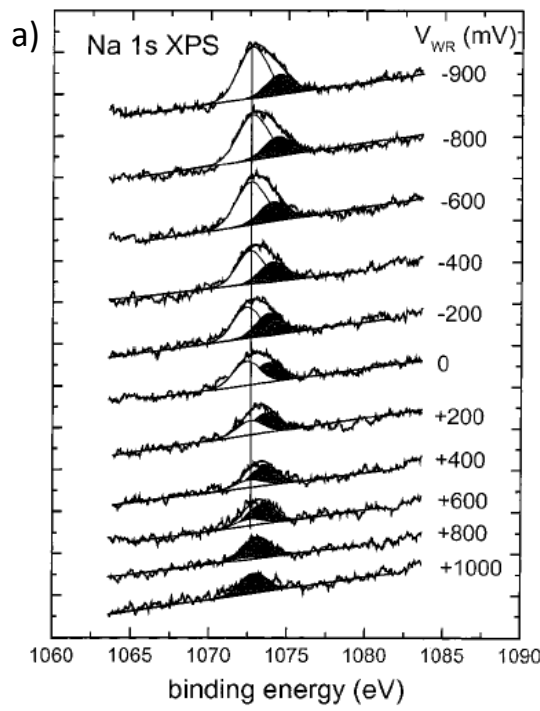

b)

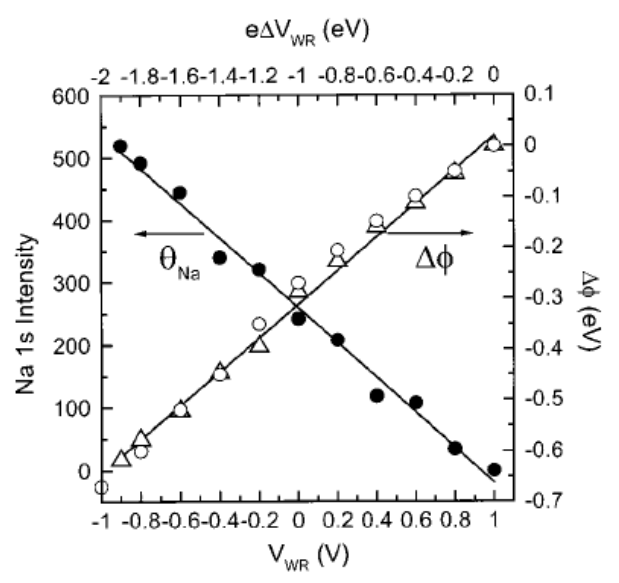

Figure 5. Na $1 \mathrm{~s}$ XPS spectra taken on a $\mathrm{Rh} / \mathrm{Na}-\mathrm{\beta Al}_{2} \mathrm{O}_{3}$ electrochemical catalyst $(580 \mathrm{~K}, \mathrm{UHV}$ conditions), showing the effect of catalyst potential $\left(V_{\mathrm{WR}}\right)$ on sodium coverage (a). Invariant component due to Na on Rh; shifting component due to Na in solid electrolyte. Influence of $V_{\mathrm{WR}}$ on the integrated $\mathrm{Na}$ 1s XPS intensity due to Na on the Rh surface and associated work function change of the catalyst film (b). Reprinted with permission from Ref. [41]. Copyright 2000 American Chemical Society. 
XPS is also a very useful technique for the in-situ identification of alkali-derived surface compounds and for the study of their formation/decomposition on the catalyst surface during the electrochemical promotion experiments. In this way, depending on the reaction atmosphere, $\mathrm{NaNO}_{2}[40], \mathrm{NaNO}_{3}[40,43-45]$ and $\mathrm{Na}_{2} \mathrm{CO}_{3}[34,37,39,43]$ were found on the electropromoted catalyst surface which, in excess, induced a poisoning effect on the catalytic activity [34,37,40]. A very illustrative example is the work carried out by Filkin et al. on propene oxidation reaction with a $\mathrm{Pt} / \mathrm{Na}-\mathrm{\beta Al}_{2} \mathrm{O}_{3}$ catalyst, where not only XPS but also X-ray excited AES and X-ray absorption near edge structure (XANES) were performed [37]. Figure 6a,b show the Na KLL Auger and Na 1s XPS spectra obtained after exposure of the catalyst to the reaction mixture and to an applied potential $\left(V_{\mathrm{WR}}\right)$ such that the Pt film was either poisoned $\left(V_{\mathrm{WR}}=-0.6 \mathrm{~V}\right.$, spectrum 1$)$, promoted $\left(V_{\mathrm{WR}}=-0.1 \mathrm{~V}\right.$, spectrum 2$)$ or electrochemically clean $\left(V_{\mathrm{WR}}=+0.5 \mathrm{~V}\right.$, spectrum 3$)$. The Na KLL auger data show that the catalyhst surface promoted at slightly negative potential presents a lower amount of Na-containing compounds than the poisoned surface (i.e., at higher negative potential), and that these promoter phases are stable at reaction temperature $(588 \mathrm{~K})$ but decomposed by pumping the $\mathrm{Na}^{+}$ions back to the solid electrolyte. Moreover, as the authors stated, during the positive polarization, the pressure in the vacuum system increased, denoting that gaseous molecules released upon decomposition of the alkali-derived compounds. The $\mathrm{Na}$ 1s XPS spectra confirm the stability of the $\mathrm{Na}^{+}$-derived compounds at reaction conditions and their decomposition under positive polarization. However, this kind of spectrometry technique does not allow distinguishing the Na loading obtained under promoted and poisoned conditions, in contrast to Auger electron spectroscopy (Figure 6a). This feature can be explained according to the different electron escape depths related to the AE and XPS spectra (with sampling depths of around 25 and $8 \AA$, respectively [37]). On the other hand, the carbon 1s XPS spectra (Figure 6c) not only confirm that the poisoned surface presents a much higher amount of $\mathrm{Na}^{+}$-derived compounds formed under reaction conditions, but also provide some proof concerning the chemical nature of these species, which likely consist of sodium carbonates, as also verified by the XANES results (Figure 6d).

In two of the previously mentioned studies $[38,46]$, scanning photoelectron microscopy (SPEM) was also used to in situ analyze the surface of $\mathrm{Cu}$ [46] and $\mathrm{Pt}$ [38] catalysts promoted by $\mathrm{Na}^{+}$and $\mathrm{K}^{+}$, respectively. For instance, Figure 7 shows the results obtained on this latter work for the alkali-promoted acetylene hydrogenation reaction. Specifically, $6.4 \mu \mathrm{m} \times 6.4 \mu \mathrm{m} \mathrm{Pt} 4 \mathrm{f}_{7 / 2}$ (raw data), $\mathrm{K} 2 \mathrm{p}_{3 / 2}$ (raw data) and topography corrected [50] $\mathrm{K} 2 \mathrm{p}_{3 / 2}$ intensity maps were taken under different applied potentials $\left(V_{\mathrm{WR}}\right)$ from $+0.4 \mathrm{~V}$ (unpromoted state) to $-0.8 \mathrm{~V}$ (electropromoted state). These micrographs show that the $\mathrm{Pt}$ signal does not attenuate as $\mathrm{K}^{+}$ions are electrochemically supplied to the catalyst film and that a very small thermal drift takes place during the experiment. On the other hand, after correcting the intensity modulations derived from topography, the $K 2 p_{3 / 2}$ maps show that the alkali promoter is relatively uniformly distributed on the Pt surface, and that its concentration clearly increases upon decreasing $V_{\mathrm{WR}}$.

Furthermore, it should be mentioned that the back-spillover phenomenon with alkaline ions has also been confirmed by scanning tunneling microscopy (STM) over Pt catalysts [51-53]. In these studies, unfiltered STM images were firstly obtained from an air-exposed $\mathrm{Pt}(111)$ catalyst film deposited on a $\mathrm{Na}-\mathrm{\beta Al}_{2} \mathrm{O}_{3}$ solid electrolyte, under open circuit conditions, i.e., before applying any electric current or potential. In this way, a $\mathrm{Pt}(111)-(2 \times 2)-\mathrm{O}$ adlattice (interatomic distance of $5.6 \AA$ ) was found along with an overlapping $\operatorname{Pt}(111)-(12 \times 12)-N a$ adlattice (interatomic distance of $33.2 \AA$ ) in some regions, the latter being attributed to thermal diffusion of sodium from the $\mathrm{Na}-\mathrm{BAl}_{2} \mathrm{O}_{3}$ during the deposition of the $\mathrm{Pt}(111)$ film [51-53]. Then, STM was carried out under both unpromoted and electropromoted established conditions. In the first case, after the application of a positive current or potential, only the $\mathrm{Pt}(111)-(2 \times 2)-\mathrm{O}$ adlattice remained on the micrograph, thus denoting a Na-free catalyst surface. This demonstrates that an unpromoted (reference) state can be defined by applying a positive enough potential on the catalyst film supported on an alkaline solid electrolyte. In the second case, after applying a negative current (of the order of $-1 \mu \mathrm{A}$ ) for a few minutes, the $\operatorname{Pt}(111)-(12 \times 12)-\mathrm{Na}$ adlattice 
reappeared [51-53]. Then, all these studies show that the origin of alkali-EPOC is clearly due to the reversible migration (back-spillover) of alkali ions to the catalyst surface. These ions may interact with co-adsorbed reactant molecules depending on the reaction conditions forming a wide variety of surface compounds and altering the chemisorption properties of the catalyst in a pronounce and controllable way.
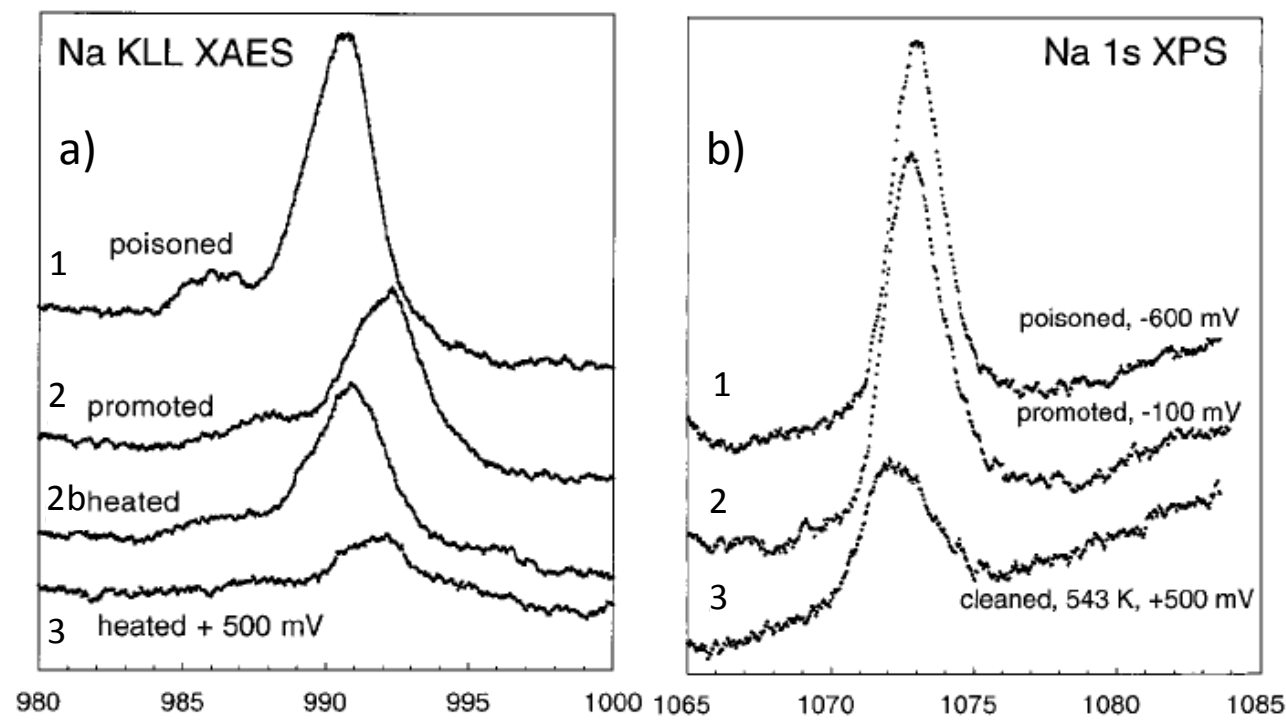

Kinetic Energy / eV
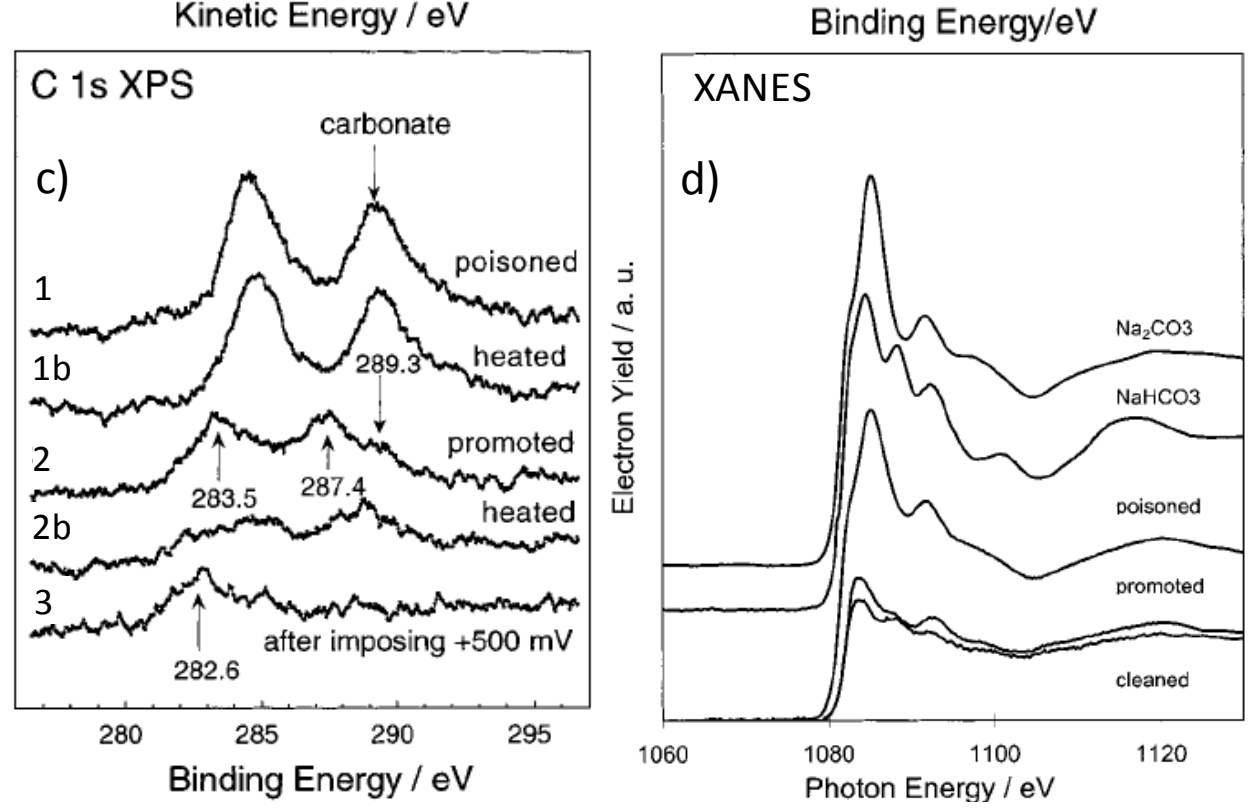

Figure 6. (a) Sodium KLL XAES, (b) Sodium 1s XPS and (c) Carbon 1s XPS analysis of a Pt/Na- $\mathrm{BAl}_{2} \mathrm{O}_{3}$ electrochemical catalyst under propene combustion atmosphere (0.6 kPa propene, $2.5 \mathrm{kPa}$ oxygen). All spectra acquired at room temperature, open circuit, after exposure to different un-promoted and electropromoted conditions: 1 , poisoned conditions, $V_{\mathrm{WR}}=-600 \mathrm{mV} ; 1 b$, as 1 but after heating to $588 \mathrm{~K} ; 2$, promoted conditions, $V_{\mathrm{WR}}=-100 \mathrm{mV}$; $2 b$, as 2 but after heating to $588 \mathrm{~K} ; 3$, as 2 but after imposing $V_{\mathrm{WR}}=+500 \mathrm{mV}$. (d) XANES spectra after exposure to propene and oxygen at $500 \mathrm{~K}$ under promoted and poisoned conditions (See Ref. [37] for temperature and partial pressures conditions). Reference XANES spectra for the cleaned surface, $\mathrm{Na}_{2} \mathrm{CO}_{3}$ and $\mathrm{NaHCO}_{3}$ are also shown. Reprinted with permission from Ref. [37]. 


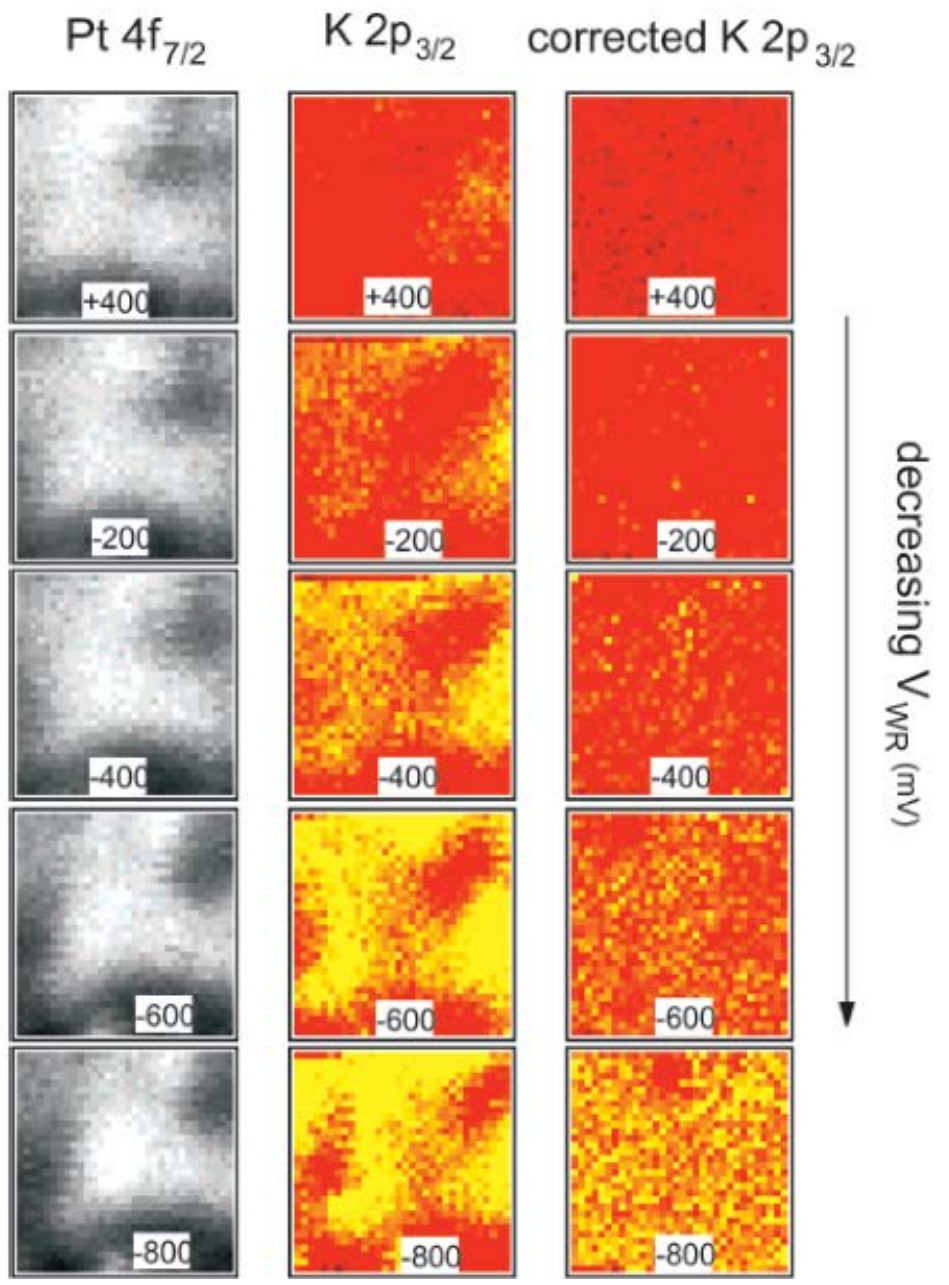

Figure 7. $\mathrm{Pt} 4 \mathrm{f} 7 / 2$ and $\mathrm{K} 2 \mathrm{p} 3 / 2$ photoelectron intensity maps taken on a $\mathrm{Pt} / \mathrm{K}-\mathrm{\beta Al}_{2} \mathrm{O}_{3}$ catalyst as a function of $V_{\mathrm{WR}}$ at $473 \mathrm{~K}$ during the selective hydrogenation of acetylene. Reprinted with permission from Ref. [38].

Finally, it should be noted that there is a kind of in situ characterization methodology called operando which is acquiring increasing interest in the catalysis scientific community and could be also very helpful in the study of the alkaline electrochemical promotion. This methodology is based on the in situ characterization of the catalyst surface while the catalytic activity is simultaneously measured, under real working conditions. However, the perfect correlation between the catalytic activity measurement and the surface analysis is very difficult mainly due to problems arising from the operando cell reactor design. This reactor cell must operate under specific pressure and temperature conditions while keeping the three-electrode configuration and allowing the spectra collection under such reaction conditions. Moreover, the presence of spectator species in the reaction and void volumes in the reactor, which are typically high for gas phase reactions, may affect the obtained spectra. Thus, new insights in the in situ characterization of the EPOC phenomenon could be opened in so far as the operando reactor design is improved and such limitations are overcome.

\section{Conclusions and Prospects}

It is well known that alkali promoters play a key role in heterogeneous catalysis with special emphasis on catalytic reactions of large scale industrial application such as ammonia or hydrocarbons synthesis. As classical alkali promotion, the phenomenon of electrochemical promotion of catalysis (EPOC) is based on the addition of promoting species to the catalyst active surface in order to modify 
its chemisorptive properties and, hence, its activity and selectivity. However, in the case of EPOC, the electrically induced back-spillover of the promoter species enables the straightforward study of the promoting role of certain alkali coverage and the in situ, controlled, enhancement of the catalytic performance under dynamic reaction conditions. For this reason, it becomes essential the employment of proper surface analysis techniques which allow monitoring the amount and state of the promoter phases as well as a deep understanding of the back-spillover phenomenon. In this sense, several ex situ and in situ characterization techniques have been carried out for the last two decades that have been described on this paper.

Although the ex situ surface analysis techniques involve a series of inaccuracies derived from the necessary handling and transfer of the electrochemical catalyst to the characterization equipment, they may constitute a useful and easy tool to determine the stability of the electrochemical catalyst and to obtain qualitative information about the different species adsorbed on the catalyst surface. On the other hand, the in situ characterization techniques provide detailed information about the mechanism of alkali ions backspillover, the nature of the promoter-derived surface compounds and their influence on the catalytic properties, as a function of both the catalyst potential variation and the reaction conditions. Hence, the implementation of surface analysis techniques herein mentioned and other possible such as fourier transform infrared (FTIR) spectroscopy, photoelectron emission microscopy (PEEM), or atomic force microscopy (AFM), in conjunction with the development of alkaline electrochemical promotion experiments, is of paramount importance not only for better understanding of this phenomenon, but also for the design of more efficient and competitive conventional heterogeneous catalysts.

Acknowledgments: The financial support of the Spanish Government and European Union is gratefully acknowledged. The authors also thank all nice scientist, colleagues and co-workers in the EPOC field.

Author Contributions: Jesús Gonzalez Cobos was the primary author of this review, selecting and discussing the most important results published on the field. Antonio de Lucas Consuegra provided assistance in writing, revising the case studies and updating the article in response to the reviewers.

Conflicts of Interest: The authors declare no conflict of interest.

\section{References}

1. Mross, W.D. Alkali doping in heterogeneous catalysis. Catal. Rev. 1983, 25, 591-637. [CrossRef]

2. Farrauto, R.J.; Bartholomew, C.H. Fundamentals of Industrial Catalytic Processes; Chapman \& Hall: London, UK, 1997.

3. Vayenas, C.G.; Bebelis, S.; Pliangos, C.S.; Brosda, D. Tsiplakides, Electrochemical Activation of Catalysis: Promotion, Electrochemical Promotion and Metal-Support Interactions; Kluwer Academic Publishers/Plenum Press: New York, NY, USA, 2001.

4. Gellings, P.J.; Bouwmeester, H.J.M. The CRC Handbook of Solid State Electrochemistry; CRC Press: Boca Raton, FL, USA, 1997.

5. Stoukides, M.; Vayenas, C.G. The effect of electrochemical oxygen pumping on the rate and selectivity of ethylene oxidation on polycrystalline silver. J. Catal. 1981, 70, 137-146. [CrossRef]

6. De Lucas-Consuegra, A. New trends of Alkali Promotion in Heterogeneous Catalysis: Electrochemical Promotion with Alkaline Ionic Conductors. Catal. Surv. Asia 2015, 19, 25-37. [CrossRef]

7. Vernoux, P.; Lizarraga, L.; Tsampas, M.N.; Sapountzi, F.M.; de Lucas-Consuegra, A.; Valverde, J.L.; Souentie, S.; Vayenas, C.G.; Tsiplakides, D.; Balomenou, S.; Baranova, E.A. Ionically conducting ceramics as active catalyst supports. Chem. Rev. 2013, 113, 8192-8260.

8. Vayenas, C.G.; Bebelis, S.; Despotopoulou, M. Non-faradaic electrochemical modification of catalytic activity 4. The use of $\beta^{\prime \prime}-\mathrm{Al}_{2} \mathrm{O}_{3}$ as the solid electrolyte. J. Catal. 1991, 128, 415-435. [CrossRef]

9. Karavasilis, C.; Bebelis, S.; Vayenas, C.G. In situ controlled promotion of catalyst surfaces via NEMCA: The effect of $\mathrm{Na}$ on the Ag-catalyzed ethylene epoxidation in the presence of chlorine moderators. J. Catal. 1996, 160, 205-213.

10. Petrolekas, P.D.; Brosda, S.; Vayenas, C.G. Electrochemical promotion of Pt catalyst electrodes deposited on $\mathrm{Na}_{3} \mathrm{Zr}_{2} \mathrm{Si}_{2} \mathrm{PO}_{12}$ during ethylene oxidation. J. Electrochem. Soc. 1998, 145, 1469-1477. [CrossRef] 
11. Yentekakis, I.V.; Moggridge, G.; Vayenas, C.G.; Lambert, R.M. In Situ controlled promotion of catalyst surfaces via NEMCA: The effect of Na on the Pt-catalyzed CO oxidation. J. Catal. 1994, 146, 292-305. [CrossRef]

12. Kotsionopoulos, N.; Bebelis, S. In situ electrochemical modification of catalytic activity for propane combustion of $\mathrm{Pt} / \beta-\mathrm{Al}_{2} \mathrm{O}_{3}$ catalyst-electrodes. Top. Catal. 2007, 44, 379-389. [CrossRef]

13. Vernoux, P.; Gaillard, F.; Lopez, C.; Siebert, E. In-situ electrochemical control of the catalytic activity of platinum for the propene oxidation. Solid State Ionics 2004, 175, 609-613. [CrossRef]

14. Dorado, F.; de Lucas-Consuegra, A.; Vernoux, P.; Valverde, J.L. Electrochemical promotion of platinum impregnated catalyst for the selective catalytic reduction of NO by propene in presence of oxygen. Appl. Catal. B 2007, 73, 42-50. [CrossRef]

15. Palermo, A.; Lambert, R.M.; Harkness, I.R.; Yentekakis, I.V.; Mar'ina, O.; Vayenas, C.G. Electrochemical promotion by $\mathrm{Na}$ of the platinum-catalyzed reaction between $\mathrm{CO}$ and NO. J. Catal. 1996, 161, 471-479. [CrossRef]

16. Vernoux, P.; Gaillard, F.; Lopez, C.; Siebert, E. Coupling catalysis to electrochemistry: A solution to selective reduction of nitrogen oxides in lean-burn engine exhausts? J. Catal. 2003, 217, 203-208. [CrossRef]

17. Williams, F.J.; Lambert, R.M. A study of sodium promotion in Fischer-Tropsch synthesis: Electrochemical control of a ruthenium model catalyst. Catal. Lett. 2000, 70, 9-14. [CrossRef]

18. Cavalca, C.A.; Haller, G.L. Solid electrolytes as active catalyst supports: Electrochemical modification of benzene hydrogenation activity on $\mathrm{Pt} / \beta^{\prime \prime}(\mathrm{Na}) \mathrm{Al}_{2} \mathrm{O}_{3}$. J. Catal. 1998, 177, 389-395. [CrossRef]

19. Bebelis, S.; Karasali, H.; Vayenas, C.G. Electrochemical promotion of the $\mathrm{CO}_{2}$ hydrogenation on Pd/YSZ and $\mathrm{Pd} / \beta^{\prime \prime}-\mathrm{Al}_{2} \mathrm{O}_{3}$ catalyst-electrodes. Solid State Ionics 2008, 179, 1391-1395. [CrossRef]

20. Pitselis, G.E.; Petrolekas, P.D.; Vayenas, C.G. Electrochemical promotion of ammonia decomposition over Fe catalyst films interfaced with $\mathrm{K}^{+}$- \& $\mathrm{H}^{+}$- conductors. Ionics 1997, 3, 110-116.

21. Urquhart, A.J.; Keel, J.M.; Williams, F.J.; Lambert, R.M. Electrochemical Promotion by Potassium of Rhodium-Catalyzed Fischer-Tropsch Synthesis: XP Spectroscopy and Reaction Studies. J. Phys. Chem. B 2003, 107, 10591-10597. [CrossRef]

22. Urquhart, A.J.; Williams, F.J.; Lambert, R.M. Electrochemical promotion by potassium of Rh-catalysed fischer-tropsch synthesis at high pressure. Catal. Lett. 2005, 103, 137-141. [CrossRef]

23. De Lucas-Consuegra, A.; Dorado, F.; Valverde, J.L.; Karoum, R.; Vernoux, P. Electrochemical activation of Pt catalyst by potassium for low temperature CO deep oxidation. Catal. Commun. 2008, 9, 17-20. [CrossRef]

24. De Lucas-Consuegra, A.; Dorado, F.; Valverde, J.L.; Karoum, R.; Vernoux, P. Low-temperature propene combustion over $\mathrm{Pt} / \mathrm{K}-\mathrm{\beta Al}_{2} \mathrm{O}_{3}$ electrochemical catalyst: Characterization, catalytic activity measurements, and investigation of the NEMCA effect. J. Catal. 2007, 251, 474-484. [CrossRef]

25. De Lucas-Consuegra, A.; Caravaca, A.; Dorado, F.; Valverde, J.L. Pt/K- $\mathrm{AAl}_{2} \mathrm{O}_{3}$ solid electrolyte cell as a "smart electrochemical catalyst" for the effective removal of $\mathrm{NO}_{x}$ under wet reaction conditions. Catal. Today 2009, 146, 330-335. [CrossRef]

26. De Lucas-Consuegra, A.; Dorado, F.; Jiménez-Borja, C.; Valverde, J.L. Influence of the reaction conditions on the electrochemical promotion by potassium for the selective catalytic reduction of $\mathrm{N}_{2} \mathrm{O}_{\text {by }} \mathrm{C}_{3} \mathrm{H}_{6}$ on platinum. Appl. Catal. B 2008, 78, 222-231. [CrossRef]

27. Ruiz, E.; Cillero, D.; Martínez, P.J.; Morales, Á.; Vicente, G.S.; De Diego, G.; Sánchez, J.M. Bench scale study of electrochemically promoted catalytic $\mathrm{CO}_{2}$ hydrogenation to renewable fuels. Catal. Today 2013, 210, 55-66. [CrossRef]

28. Ruiz, E.; Cillero, D.; Martínez, P.J.; Morales, Á.; Vicente, G.S.; de Diego, G.; Sánchez, J.M. Electrochemical synthesis of fuels by $\mathrm{CO}_{2}$ hydrogenation on $\mathrm{Cu}$ in a potassium ion conducting membrane reactor at bench scale. Catal. Today 2014, 236, 108-120. [CrossRef]

29. Makri, M.; Katsaounis, A.; Vayenas, C.G. Electrochemical promotion of $\mathrm{CO}_{2}$ hydrogenation on $\mathrm{Ru}$ catalyst-electrodes supported on a $\mathrm{K}-\beta^{\prime \prime}-\mathrm{Al}_{2} \mathrm{O}_{3}$ solid electrolyte. Electrochim. Acta 2015, 179, 556-564.

30. Gutiérrez-Guerra, N.; González-Cobos, J.; Serrano-Ruiz, J.C.; Valverde, J.L.; de Lucas-Consuegra, A. Electrochemical Activation of Ni Catalysts with Potassium Ionic Conductors for $\mathrm{CO}_{2}$ Hydrogenation. Top. Catal. 2015, 58, 1256-1269. [CrossRef]

31. De Lucas-Consuegra, A.; González-Cobos, J.; García-Rodríguez, Y.; Mosquera, A.; Endrino, J.L.; Valverde, J.L. Enhancing the catalytic activity and selectivity of the partial oxidation of methanol by electrochemical promotion. J. Catal. 2012, 293, 149-157. [CrossRef] 
32. González-Cobos, J.; Rico, V.J.; González-Elipe, A.R.; Valverde, J.L.; de Lucas-Consuegra, A. Electrochemical activation of an oblique angle deposited $\mathrm{Cu}$ catalyst film for $\mathrm{H}_{2}$ production. Catal. Sci. Tec. 2015, 5, 2203-2214. [CrossRef]

33. González-Cobos, J.; López-Pedrajas, D.; Ruiz-López, E.; Valverde, J.L.; de Lucas-Consuegra, A. Applications of the Electrochemical Promotion of Catalysis in Methanol Conversion Processes. Top. Catal. 2015, 58, 1290-1302. [CrossRef]

34. Harkness, I.R.; Hardacre, C.; Lambert, R.M.; Yentekakis, I.V.; Vayenas, C.G. Ethylene oxidation over platinum: In situ electrochemically controlled promotion using Na- $\beta^{\prime \prime}$ alumina and studies with a $\mathrm{Pt}(111) / \mathrm{Na}$ model catalyst. J. Catal. 1996, 160, 19-26. [CrossRef]

35. Konsolakis, M.; Palermo, A.; Tikhov, M.; Lambert, R.M.; Yentekakis, I.V. Electrochemical vs. conventional promotion: A new tool to design effective, highly dispersed conventional catalysts. Ionics 1998, 4, 148-156. [CrossRef]

36. Lambert, R.M.; Tikhov, M.; Palermo, A.; Yentekakis, I.V.; Vayenas, C.G. Electrochemical promotion of environmentally important catalytic reactions. Ionics 1995, 1, 366-376. [CrossRef]

37. Filkin, N.C.; Tikhov, M.S.; Palermo, A.; Lambert, R.M. A Kinetic and Spectroscopic Study of the in Situ Electrochemical Promotion by Sodium of the Platinum-Catalyzed Combustion of Propene. J. Phys. Chem. A 1999, 103, 2680-2687. [CrossRef]

38. Williams, F.J.; Palermo, A.; Tracey, S.; Tikhov, M.S.; Lambert, R.M. Electrochemical promotion by potassium of the selective hydrogenation of acetylene on platinum: Reaction studies and XP spectroscopy. J. Phys. Chem. B 2002, 106, 5668-5672. [CrossRef]

39. Williams, F.J.; Palermo, A.; Tikhov, M.S.; Lambert, R.M. Electrochemical promotion by sodium of the rhodium-catalyzed reduction of NO by propene: Kinetics and spectroscopy. J. Phys. Chem. B 2001, 105, 1381-1388. [CrossRef]

40. Yentekakis, I.V.; Palermo, A.; Filkin, N.C.; Tikhov, M.S.; Lambert, R.M. In situ electrochemical promotion by sodium of the platinum-catalyzed reduction of NO by propene. J. Phys. Chem. B 1997, 101, 3759-3768. [CrossRef]

41. Williams, F.J.; Palermo, A.; Tikhov, M.S.; Lambert, R.M. Electrochemical promotion by sodium of the rhodium-catalyzed NO + CO reaction. J. Phys. Chem. B 2000, 104, 11883-11890. [CrossRef]

42. Williams, F.J.; Palermo, A.; Tikhov, M.S.; Lambert, R.M. Mechanism of alkali promotion in heterogeneous catalysis under realistic conditions: Application of electron spectroscopy and electrochemical promotion to the reduction of NO by CO and by propene over rhodium. Surf. Sci. 2001, 482-485, 177-182.

43. Williams, F.J.; Tikhov, M.S.; Palermo, A.; Macleod, N.; Lambert, R.M. Electrochemical promotion of rhodium-catalyzed NO reduction by $\mathrm{CO}$ and by propene in the presence of oxygen. J. Phys. Chem. B 2002, 105, 2800-2808. [CrossRef]

44. Lambert, R.M.; Williams, F.; Palermo, A.; Tikhov, M.S. Modelling alkali promotion in heterogeneous catalysis: In situ electrochemical control of catalytic reactions. Top. Catal. 2000, 13, 91-98. [CrossRef]

45. Williams, F.J.; Palermo, A.; Tikhov, M.S.; Lambert, R.M. First Demonstration of in Situ Electrochemical Control of a Base Metal Catalyst: Spectroscopic and Kinetic Study of the CO + NO Reaction over Na-Promoted Cu. J.Phys. Chem. B 1999, 103, 9960-9966. [CrossRef]

46. Williams, F.J.; Palermo, A.; Tikhov, M.S.; Lambert, R.M. The Origin of Electrochemical Promotion in Heterogeneous Catalysis: Photoelectron Spectroscopy of Solid State Electrochemical Cells. J. Phys. Chem. B 2000, 104, 615-621. [CrossRef]

47. Carley, A.F.; Roberts, M.W. X-ray photoelectron spectroscopic study of the interaction of oxygen and nitric oxide with aluminium. Proc. R. Soc. London Ser. A 1978, 363, 403-424. [CrossRef]

48. Vayenas, C.G.; Bebelis, S.; Ladas, S. Dependence of catalytic rates on catalyst work function. Nature 1990, 343, 625-627. [CrossRef]

49. Yentekakis, I.V.; Lambert, R.M.; Tikhov, M.S.; Konsolakis, M.; Kiousis, V. Promotion by sodium in emission control catalysis: A kinetic and spectroscopic study of the Pd-catalyzed reduction of NO by propene. J. Catal. 1998, 176, 82-92. [CrossRef]

50. Günther, S.; Kolmakov, A.; Kovac, J.; Kiskinova, M. Artefact formation in scanning photoelectron emission microscopy. Ultramicroscopy 1998, 75, 35-51. [CrossRef]

51. Makri, M.; Vayenas, G.G.; Bebelis, S.; Besocke, K.H.; Cavalca, C. Atomic resolution STM imaging of electrochemically controlled reversible promoter dosing of catalysts. Surf. Sci. 1996, 369, 351-359. [CrossRef] 
52. Makri, M.; Vayenas, C.G.; Bebelis, S.; Besocke, K.H.; Cavalca, C. Atomic resolution scanning tunneling microscopy imaging of Pt electrodes interfaced with $\beta^{\prime \prime}-\mathrm{Al}_{2} \mathrm{O}_{3}$. Ionics 1996, 2, 248-253. [CrossRef]

53. Archonta, D.; Frantzis, A.; Tsiplakides, D.; Vayenas, C.G. STM observation of the origin of electrochemical promotion on metal catalyst-electrodes interfaced with YSZ and $\beta^{\prime \prime}-\mathrm{Al}_{2} \mathrm{O}_{3}$. Solid State Ionics 2006, 177, 2221-2225. [CrossRef] 